\title{
Potencialidades de um sistema web para apoio a aprendizagem na pandemia de COVID-19 utilizando métodos efetivos para construção do conhecimento
}

\author{
Potential of a web system to support learning in the COVID-19 pandemic using effective methods \\ for knowledge construction
}

Potencial de un sistema web para apoyar el aprendizaje en la pandemia COVID-19 utilizando métodos efectivos para la construcción del conocimiento

Recebido: 25/08/2021 | Revisado: 03/09/2021 | Aceito: 04/09/2021 | Publicado: 06/09/2021

\author{
Mislene Dalila da Silva \\ ORCID: https://orcid.org/0000-0002-5657-4754 \\ Universidade Federal de Uberlândia, Brasil \\ E-mail: mislenedalila@gmail.com \\ Luciano Vieira Lima \\ ORCID: https://orcid.org/0000-0003-0298-5467 \\ Universidade Federal de Uberlândia, Brasil \\ E-mail: lucianovieiralimaster@gmail.com
}

\begin{abstract}
Resumo
Este trabalho apresenta as potencialidades de um sistema web que implementa uma interface entre o professor e o aluno através do ensino remoto, para ser utilizado como complemento para aprendizagem nesse período de pandemia de COVID-19. Onde possibilita ambos uma interface de conhecimento, tanto para o aluno, quanto para o professor. No qual o professor disponibiliza material que é realmente do seu domínio e competente ao que ele deseja mediar de conhecimento para o aluno, evitando que o mesmo acesse materiais divergentes do que será cobrado em situações que deve expor o conhecimento e que o aluno consiga abstrair desse conteúdo um conhecimento que vai ficar consolidado em sua memória. A pesquisa tem o cunho exploratória descritiva. Nesse contexto, o objetivo deste estudo foi desenvolver um sistema web que auxilie o aluno na retenção do conhecimento e na segurança de aplicar suas habilidades em situações que o requerem. Foi utilizado no sistema o algoritmo do Método de Memorização Exponencial Efetiva em Base Binária - MMEEBB, que possibilita ao indivíduo efetivamente aprender um conteúdo e reter o conhecimento em sua memória, onde o MMEEBB cria intervalos de reforços de aprendizagem que devem ser seguidos para manter o conhecimento consolidado.
\end{abstract}

Palavras-chave: Sistemas de aprendizagem; Pandemia; COVID-19; Retenção de conhecimento; Aprendizagem por memorização; Ferramentas digitais de ensino.

\begin{abstract}
This work presents the potential of a web system that implements an interface between the teacher and the student through remote teaching, to be used as a complement for learning in this period of the COVID-19 pandemic. Where it enables both a knowledge interface, both for the student and for the teacher. In which the teacher makes available material that is really in their domain and competent to what they want to mediate knowledge for the student, preventing them from accessing material divergent from what will be placed in situations that should expose the knowledge and that the student can abstract from this content knowledge that will be consolidated in your memory. The research has an exploratory-descriptive nature. In this context, the objective of this study was to develop a web system that helps the student in retaining knowledge and in the security of applying their skills in hypotheses that the impediment. The algorithm of the Effective Exponential Memory Method in Binary Base - MMEEBB was used in the system, which allows the individual to learn a content and retain it in their memory, where the MMEEBB creates intervals of learning reinforcements that must be followed to maintain consolidated knowledge.
\end{abstract}

Keywords: Learning systems; Pandemic; COVID-19; Knowledge retention; Learning by memorization; Digital teaching tools.

\section{Resumen}

Este trabajo presenta el potencial de un sistema web que implementa una interfaz entre el docente y el alumno a través de la enseñanza a distancia, para ser utilizado como complemento al aprendizaje en este período de la pandemia COVID-19. Donde permite tanto una interfaz de conocimiento, tanto para el alumno como para el profesor. En el que el docente pone a disposición material que realmente es de su dominio y competente para lo que quiere que medie conocimiento para el alumno, impidiéndole acceder a material divergente de lo que se colocará en situaciones que 
deberían exponer el conocimiento y que el alumno pueda abstraer. a partir de este contenido conocimiento que se consolidará en tu memoria. La investigación tiene un carácter exploratorio-descriptivo. En este contexto, el objetivo de este estudio fue desarrollar un sistema web que ayude al alumno en la retención de conocimientos y en la seguridad de aplicar sus habilidades en hipótesis que el impedimento. En el sistema se utilizó el algoritmo del Método de Memoria Exponencial Efectiva en Base Binaria - MMEEBB, que permite al individuo aprender un contenido y retenerlo en su memoria, donde el MMEEBB crea intervalos de refuerzos de aprendizaje que se deben seguir para mantener un conocimiento consolidado.

Palabras clave: Sistemas de aprendizaje; Pandemia; COVID-19; Retención de conocimientos; Aprendizaje por memorización; Herramientas didácticas digitales.

\section{Introdução}

Os recursos tecnológicos têm sidos amplamente evoluídos e têm possibilitados grandes benefícios em diversas áreas do mercado nos dias atuais. Neste contexto, o acesso à Internet tem cada vez mais facilitado as tarefas diárias. Segundo uma pesquisa realizada em janeiro de 2021 pelo We Are Social juntamente com o Hootsuite, o número de usuários que fazem uso da Internet, mundialmente, chegou a 4,66 bilhões em tal mês/ ano ou em tal ano (Kemp, 2021). Esses dados mostram que esse avanço tecnológico tem possibilitado que mais pessoas possam ter acesso às oportunidades proporcionadas pelo uso dos recursos tecnológicos vigentes.

Uma das áreas que tem sido beneficiada com o avanço dos recursos tecnológicos é a área educacional, por meio do uso das chamadas Tecnologias da Informação e Comunicação - TIC. As TIC são compostas por equipamentos tecnológicos como computadores, tablets, smartphones, que quando são devidamente utilizados, são capazes de potencializar o processo de aprendizagem dos alunos. Entretanto, o uso dessas TIC pode ser mais eficaz quando conciliado com o suporte de um profissional da educação, que é capaz de nortear o aluno com os devidos conteúdos que o mesmo deve estudar.

Em março de 2020 o Brasil decretou estado de calamidade pública devido a pandemia do novo coronavírus (Brasil, 2020). Medidas extremas como o lockdown tiveram que ser adotadas para evitar a disseminação do vírus. (Dias \& Pinto, 2020). Diversos setores foram diretamente impactados com essas mudanças, e um deles foi o setor da educação. Pelo fato de as escolas serem consideradas um espaço de grande aglomeração e, portanto, com alta possibilidade de contaminação, professores, pais e alunos tiveram que se adaptar com diversas mudanças no formato das aulas, que deixaram de ocorrer de forma presencial e passaram a ser realizadas por plataformas online de forma remota.

Essas mudanças acarretaram em diversas dificuldades de adaptação tanto dos alunos quanto dos pais, que se encontraram frustrados por não conseguirem dar o devido apoio na educação de seus filhos. Diversos professores também ficaram frustrados, alguns por enfrentarem dificuldade de se adaptar com o regime remoto e outros por terem seus contratos suspensos em uma época tão difícil. Desde então, estes professores tiveram que buscar meios alternativos para continuarem exercendo sua profissão, e a solução encontrada foi a execução de aulas remotas, que acabou auxiliando também na vida dos pais que desejam uma que seus filhos mantenham uma rotina de estudos. (Reis, A.V.S.A; Amaro \& Reis, F., 2020).

Nesse contexto de aulas remotas, o objetivo deste trabalho foi desenvolver um sistema web, onde o professor insere conteúdo relacionado as disciplinas que ministra, com diversos tipos de mídias e seguindo metodologias ativas de aprendizagem onde o aluno é o agente principal responsável pela sua aprendizagem. Uma dessas metodologias é o Mapa de Conhecimento Estruturado - MCE que categoriza o conteúdo para o aluno em conceitos e conhecimento e não deixa o aluno seguir para um próximo conteúdo sem que o anterior esteja consolidado, permitindo assim que o aluno tenha um melhor entendimento sobre o que aprendeu e o que tem dificuldade. Posteriormente o aluno tem acesso a um cronograma, através do Método de Memorização Exponencial Efetivo na Base Binária - MMEEBB, onde é gerado intervalos de notificações para o aluno, que devem ser seguidos para consolidar o conhecimento na memória e em momentos que necessitar utilizá-lo. Desta forma o software minimiza os impactos causados pela pandemia no que vincula a consolidação do conhecimento, oferecendo uma segurança para o aluno do conteúdo que está sendo abstraído e uma trilha de conhecimento já que com a pandemia o 
acompanhamento presencial do professor foi impossibilitado, portanto o aluno continua recebendo informações do seu professor para que não ocorra o risco dele estudar algo que não seja focado na disciplina e ainda que ele retenha o conhecimento em sua memória.

\section{Metodologia}

O estudo é do tipo exploratório de cunho descritivo e bibliográfico fundamentado em (Gil, 2002), possibilitando uma compressão das informações e dados escolhidos para a temática abordada. Buscou-se artigos na base de dados do Google Acadêmico e Scielo, por termos sobre a memorização, a afetividade e a aprendizagem ligadas a técnicas de memorização. Em seguida foi analisado os resumos dos textos, figuras, quadros, conceitos discutidos para se chegar aos resultados com o desenvolvimento do software que irá auxiliar alunos e professores (OPAS, 2021).

\section{Reflexões Sobre Memorização e a Pandemia}

No final do ano de 2019, a Organização Mundial de Saúde (OMS), foi reportada sobre diversos casos de pneumonia na cidade de Wuhan, província de Hubei, na República Popular da China. Inicialmente tratava-se de uma suspeita de doença de origem zoonótica. Em 07 de janeiro de 2020, as autoridades chinesas admitiram que tinham identificado um novo tipo de coronavírus. Os coronavírus estão por toda parte. Eles são o segundo principal motivo de resfriado comum (após rinovírus) e, até as últimas décadas, raramente causavam doenças mais graves em humanos do que o resfriado comum.

\subsection{Pandemia e Desemprego no Brasil}

A pandemia do Covid-19, cientificamente identificado por SARS-CoV-2, vem causando diversos impactos negativos não somente de ordem epidemiológica, mas também de ordem social, econômica e política (Portal fio cruz, 2020). O número assustador de contágios e mortes fez com que os órgãos governamentais fossem obrigados a tomarem medidas extremas de prevenção e decretassem estado de calamidade pública, como ocorrido no Brasil em março de 2020 (Brasil, 2020).

O isolamento social foi uma das medidas implementadas por diversos países com objetivo de conter o avanço do vírus. Esta medida comprovou-se eficaz em um compilado de 19 estudos do Instituto Cochrane, que apontou que tal medida juntamente com a adoção da quarentena é capaz reduzir as chances de mortes pela doença de 31\% a 63\% (Ruprecht, 2020).

Embora o isolamento social tenha eficácia comprovada contra a disseminação do vírus, tal medida ocasionou diversos impactos socioeconômicos negativos. Com o fechamento das escolas, universidades, comércios, entre outros, a taxa de desemprego teve um aumento significativo. Uma pesquisa do IBGE mostrou que em agosto de 2020 a taxa de desocupação no Brasil atingiu 14,3\%, um aumento de 1,1\% em relação a pesquisas anteriores. Esses números representam um total de mais 1,1 milhão de pessoas desempregadas (Agência Brasil, 2020).

\subsection{Pandemia e educação: importância das aulas remotas}

Em decorrência do alto risco de contágio causado pelo Novo Coronavírus, em março de 2020 foi decretado por tempo indeterminado a suspensão das atividades escolares presenciais de escolas e universidades (Lupion, 2020).

Com a suspensão das atividades presenciais, instituições tiveram que adotar o regime de aulas remotas para que a educação dos alunos não ficasse em todo comprometida. No entanto, foi notado uma grande dificuldade de adaptação com a adoção desse regime, principalmente nos alunos que compõe a educação infantil. Devido a essa dificuldade de adaptação, houve uma grande redução na quantidade de alunos, principalmente de rede particular. Essa redução influenciou na suspensão do contrato de diversos professores, que foram pegos de surpresa com essa notícia. (Monteiro, 2020).

Uma pesquisa apontou que desde o início da pandemia, cerca de 1.300 professores da rede particular de ensino foram 
demitidos somente no Distrito Federal (Salomão, 2021). Diante deste cenário incerto de mudanças, professores passaram a buscar alternativas para continuarem exercendo sua profissão. Levando em consideração a frustração também vivida pelos pais, que puderam sentir o impacto das dificuldades encontradas em auxiliarem na educação de seus filhos, a alternativa encontrada para resolver esse impasse enfrentado por ambas as partes foi a adoção de aulas particulares. (Rocha et al, 2020).

A adoção dessas aulas fez com que ambas as partes pudessem ser beneficiadas. Os professores voltaram a ter um pouco de esperança por serem contratados e os pais afirmam que excelentes resultados puderam ser notados após a adoção de professores particulares. Relatam ainda que embora os alunos tenham acesso às aulas online, é difícil fazer com que eles se mantenham focados nas atividades e tenham um aprendizado eficaz (Morais, 2020). A contratação de um professor particular faz com que o aluno possa ter um acompanhamento com um profissional dedicado, e, portanto, seu ensino será mais eficiente.

\subsection{Método de Memorização Exponencial Efetivo na Base Binária - MMEEBB}

O MMEEBB é o inverso conceitual da Forgeting Curve - Curva de Esquecimento de Hermann Ebbinghaus. (Flashcard,2020). Pois, o MMEEBB, desenvolve a Curva de Memorização Exponencial Efetiva - CME que trabalha com o Intervalo do Reforço do Aprendizado - IRA, onde apresenta o valor máximo de intervalo temporal para memorização,

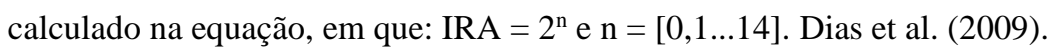

A CME apresenta quando o indivíduo tem que realizar o reforço da informação para reter o conhecimento em sua memória. Nesse contexto, não é aferido quando se esquece a informação, mas quando vai ter que realizar o processo para memorizar (Silva, 2017). Na Figura 1, é apresentado que a CME é efetiva e exponencial, assim como a Forgeting Curve, porém é utilizada para a retenção do conhecimento, com a inserção de reforços de memorização.

Figura 1: Curva de Memorização Efetiva.

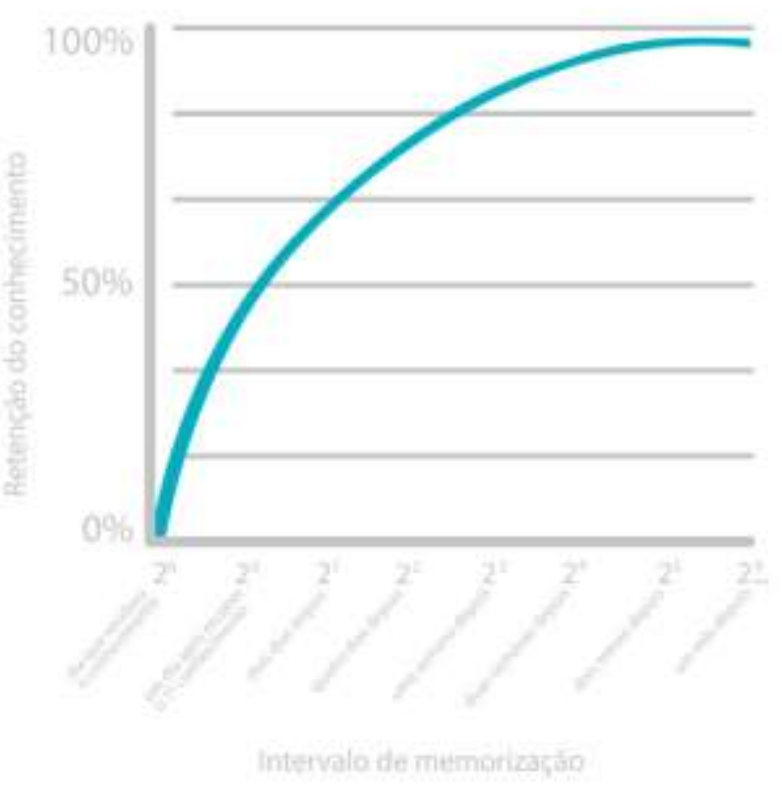

Fonte: Adaptado Dias et al. (2009, p. 87).

Como pode ser observado, o conhecimento se mantém perene na medida que o reforço do $2^{\mathrm{n}}$ é administrado. A cada intervalo do $2^{\mathrm{n}}$ a memorização deve ser reiniciada. Isso se deve pela aplicação do processo exponencial, onde o último intervalo para memorização em dias é igual a $2^{14}$.

A aplicação do MMEEBB foi testada por Dias et al. (2009). Após um intervalo de tempo, o $2^{\mathrm{n}}$ apresenta valores em décadas, demonstrando o evento de pessoas idosas recordarem todos os fatos de sua infância e adolescência e não recordar 
fatos da semana anterior, por exemplo. Esse fenômeno é explicado devido ao fato de a memória guardar e ter acessos às informações através de pontes eletroquímicas.

Com a aplicabilidade do método é recomendado, que as repetições seguindo o intervalo $2^{\mathrm{n}}$, sejam cumpridas pelo indivíduo, caso a mesma não seja cumprida na sequência correta, deve se iniciar do raio zero, ou seja, do primeiro dia que recebeu o conhecimento. Com a aplicação do método, a memorização torna-se extensa e ativa (Carneiro, 2017).

O processo de memorização do conhecimento pode ser realizado de formas diferente, a indicação é que seja dessa forma, não apenas lendo resumos, relendo textos ou repetindo exercícios. O reforço ativo é indicado, ou seja, aplicar o conhecimento adquirido, promovendo debates em conversas com temas aderentes, fazendo autoquestionamentos, entre outras ações (Silva, 2020).

\subsection{Mapa de Conhecimento Estruturado - MCE}

A estrutura do MCE garante que um estudante nunca passe ao aprendizado de um novo conhecimento sem antes ter pleno domínio do conhecimento precedente. Neste método, para evitar a sobrecarga cognitiva, excesso de informação, (Cowan, 2001), o conteúdo/ementa do curso deve ser quebrado em objetos, ou seja, conceitos e definições e morfismos, conhecimentos, (Ferreira, 2014).

As parcelas dos conteúdos são divididas em etapas com conhecimentos antecedentes e consequentes. Assim, não pode faltar conhecimentos dos pré-requisitos exigidos para inicializar o processo de aprendizagem do novo conhecimento. Para isto, no MCE têm duas estruturas denominadas de raio de conhecimento e a área de ignorância, como pode ser visualizado na Figura 2. Um círculo, onde o raio representa o conhecimento do estudante ou o conhecimento que se deseja transmitir. A área do círculo representa a ignorância que este raio desencadeia no estudante. (Lima, 2013).

Figura 2: Raio de conhecimento e área de ignorância.

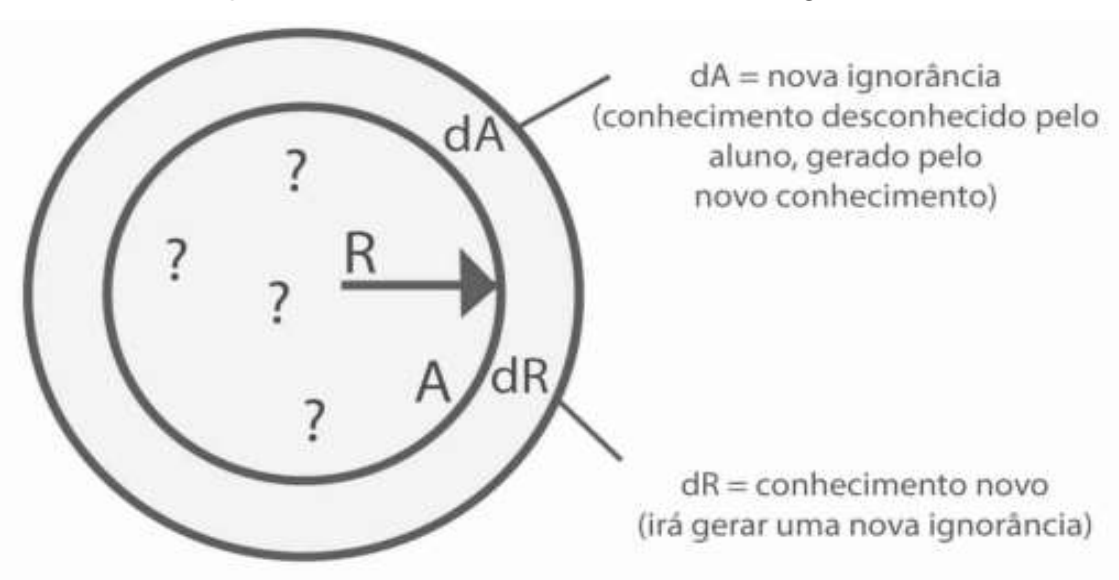

Fonte: Ferreira (2014), 508.

\section{Software Proposto para Efetivar o Conhecimento}

Este trabalho propõe o desenvolvimento de um sistema onde o professor, insere conteúdo relacionado as disciplinas que ministra, com diversos tipos de mídias e seguindo metodologia ativas de aprendizagem uma delas o Mapa de conhecimento estruturado - MCE que categoriza o conteúdo para o aluno em conceitos e conhecimento e não deixa o aluno seguir para um próximo conteúdo sem que o anterior esteja consolidado, posteriormente o aluno tem acesso utilizando métodos efetivos que retém o conhecimento em sua memória, através do Método de Memorização Exponencial Efetivo na Base Binária - MMEEBB, onde é gerado intervalos de notificações para o aluno, que devem ser seguidos para consolidar o conhecimento 
na memória e em momentos que necessitar utilizá-lo.

Para interpretar e apresentar de maneira fluida os passos que o professor e o aluno podem trilhar no sistema, foi desenvolvido um fluxo com as funções que o aluno e professor podem seguir no sistema, apresentado na Figura 3. Como já destacado, o objetivo foi criar um ambiente personalizado e adaptativo a fim de que pessoas que vão utilizar de sistemas remotos para aprendizagem devido os impactos do Novo Coronavírus e seguido as diretrizes de distanciamento impostas, possam aprender de acordo seu próprio ritmo de aprendizagem, mantendo perene esse aprendizado abstraído e tendo segurança de que realmente aprendeu.

Na Figura 03, o professor tem responsabilidade de gerir informações no sistema, tais como: gerenciar área de conteúdo, conteúdo programático que são os tópicos detalhados que vão ser abordados no conteúdo disponibilizado, inserção do material que pode ser tipos de mídias em pdf, imagens, infográficos, vídeos e áudios, a inserção de material e conteúdo complementar e ainda a gestão de usuários que o mesmo irá liberar para ter acesso ao conteúdo.

No perfil aluno é possível visualizar o cronograma para memorização gerado para cada conteúdo de acordo com a data de início, selecionar conteúdos que possui dúvida para iniciar o conhecimento, definir os tipos de mídias que prefere aprender, visualizar materiais e ainda excluir os conteúdos que já foram consolidados.

Figura 3: Perfis de usuários no sistema.

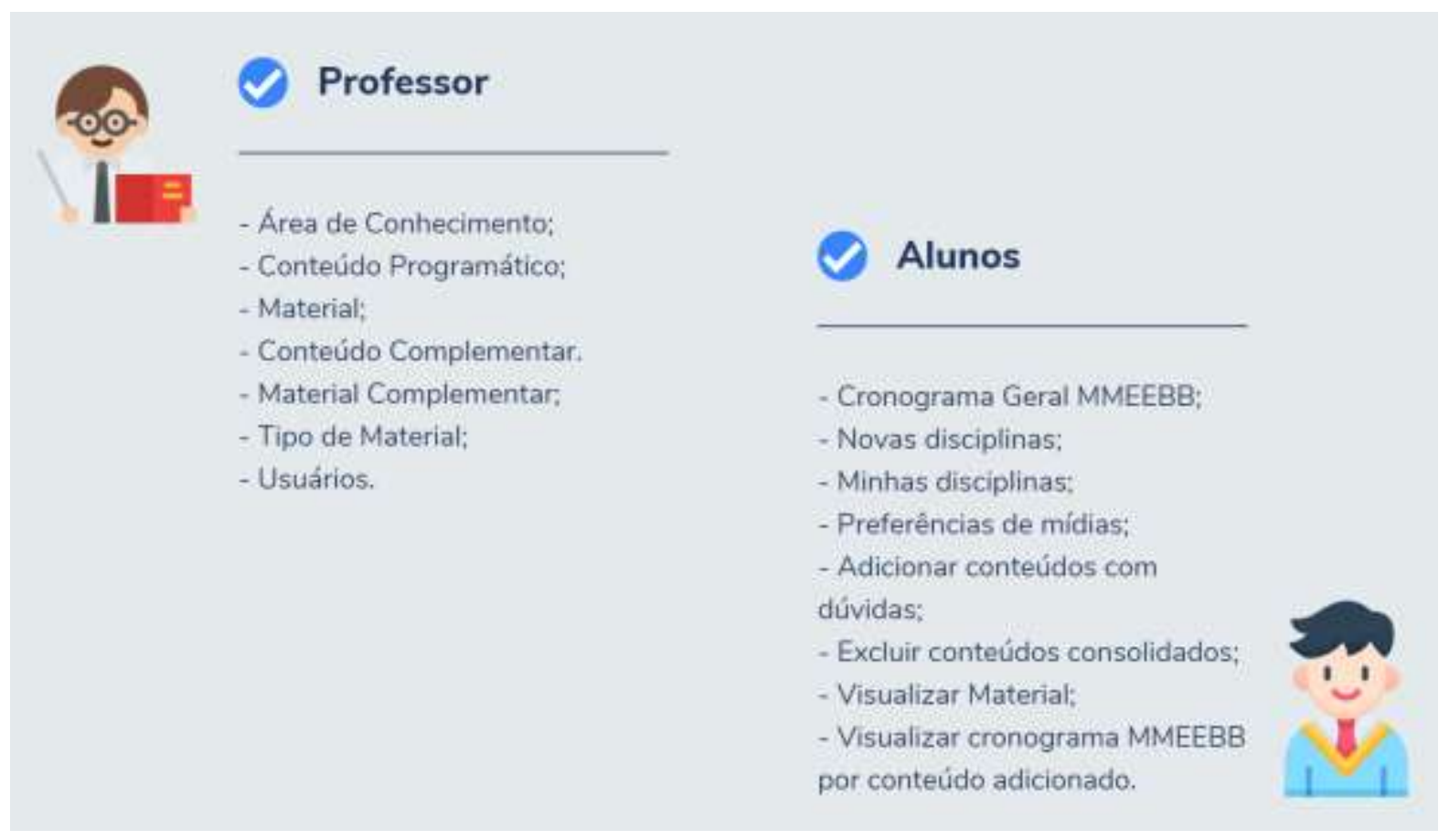

Fonte: Autores (2021).

$\mathrm{O}$ ato de recordar está vinculado ao método que é executado para memorizar, se são aplicadas recordações ativas ou passivas. A recordação ativa é a ação, fazer uma pergunta para o aluno ou solicitar que ele confronte uma notícia de acordo com o material que foi revisado por ele, ou seja, avaliar, de alguma forma, o que foi estudado, sem replicar o conteúdo, com estudos de caso. Já a recordação passiva é o processo em que é aplicado o mesmo conteúdo para o aluno ler novamente, ou seja, replicar o conteúdo. Nos tópicos a seguir são apresentados os fluxos do professor e dos alunos. Onde são aplicados esses conceitos de recordações. 


\subsection{Fluxo do Professor}

Como pode ser observado na Figura 4, é apresentado o fluxo inicial que o professor segue no sistema. Com o perfil professor é possível realizar a inserção do conteúdo na plataforma. Inicialmente, o professor precisa inserir alguns parâmetros no sistema. Um deles são as áreas de conhecimento, que podem ser as disciplinas, por exemplo: Português, Matemática e Informática, o outro parâmetro é o tipo de material que pode ser imagem, arquivos em pdf, vídeos, infográficos entre outros. Pode-se editar, inserir e excluir essas áreas de conhecimento.

Figura 4: Fluxo Professor - Parte 1.

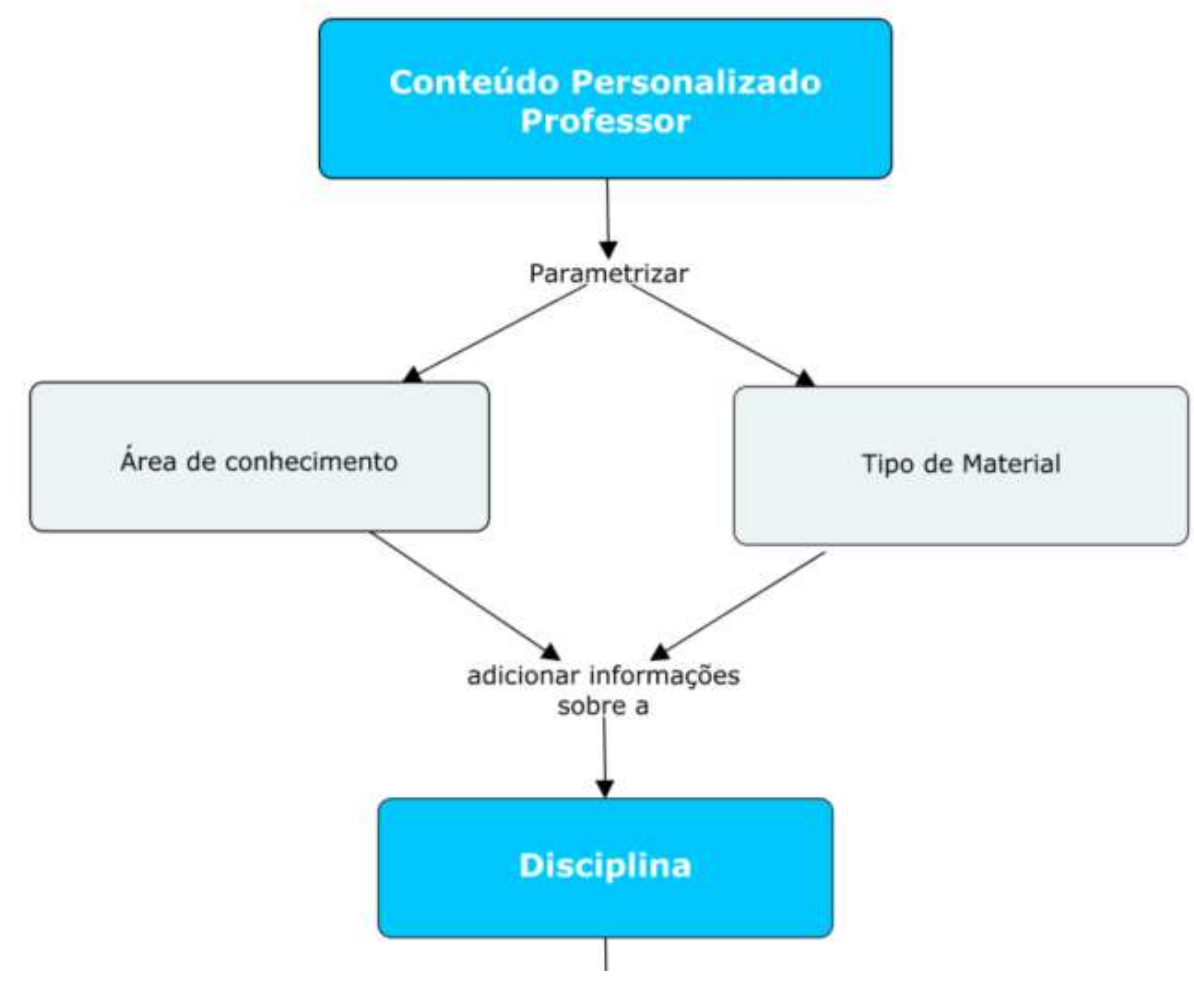

Fonte: Autores (2021).

O próximo passo a ser realizado pelo professor é a inserção do conteúdo programático da disciplina, que extraído normalmente nas instituições educacionais do Plano de Ensino da Disciplina, nessa função são adicionados o nome do conteúdo programático, a área de conhecimento que foi adicionada anteriormente e a sequência de estudos. Feito esse processo, são extraídas palavras e expressões do conteúdo programático, que são classificadas. A Figura 5, mostra como essas palavras são classificadas. 


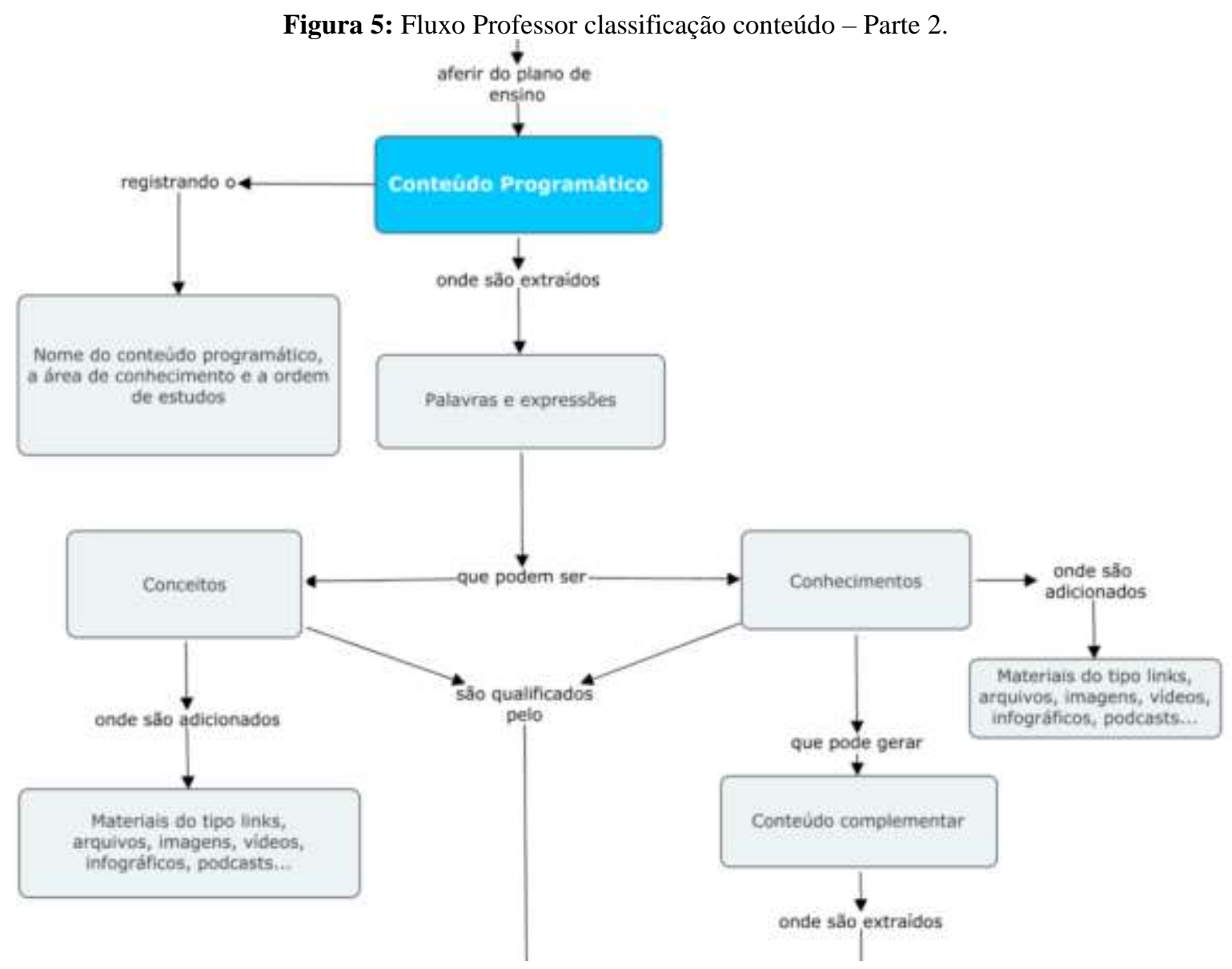

Fonte: Autores (2021).

As palavras e expressões são classificadas em conceitos e conhecimentos. Portanto, o professor precisa ter esse conhecimento sobre os Mapas de Conhecimento Estruturado para classificar o conteúdo e, assim, disponibilizá-lo para o aluno. Em ambas as classificações Conceito, conteúdo teórico, e Conhecimento, conteúdo prático que envolve uma ação, é possível inserir diversos tipos de mídias, por exemplo: imagens, vídeos, arquivos em .pdf e áudio, indicado pelo professor, que preencherá a lacuna de dúvidas do aluno referente ao conteúdo programático. Desse modo, o professor pode inserir materiais de autoria dele ou materiais de fontes externas, mas sempre lembrando que deve ser o conteúdo que realmente é compatível com o definido no plano de ensino da disciplina.

Porém, quando a classificação for do tipo Conhecimento, o professor pode gerar conteúdos complementares, como apresentado na Figura 5 pelo fluxo conteúdo complementar. Um exemplo da utilização desse conteúdo, seria o professor administrar um conteúdo sobre equações, mas o aluno ainda não tem conhecimento sobre as operações básicas que é somar, subtrair, multiplicar e dividir, portanto, ele deve aprender antes essas operações básicas, para depois ter o conhecimento sobre equações. Nesse contexto o conteúdo programático, quando classificado como Conhecimento, pode ser ramificado. Desse modo, palavras e expressões podem ser extraídas desse conteúdo programático complementar e o professor, da mesma forma, consegue realizar a inserção de materiais. Realizada essa classificação, os conteúdos e as mídias são salvos pelo professor. Como pode ser visualizado na Figura 6, os conteúdos e mídias classificados pelo professor como conceito e conhecimento podem ser salvos e, a partir desse momento, se o aluno acessar a plataforma conseguirá visualizar o material classificado e disponibilizado pelo professor. 
Research, Society and Development, v. 10, n. 11, e467101119824, 2021

(CC BY 4.0) | ISSN 2525-3409 | DOI: http://dx.doi.org/10.33448/rsd-v10i11.19824

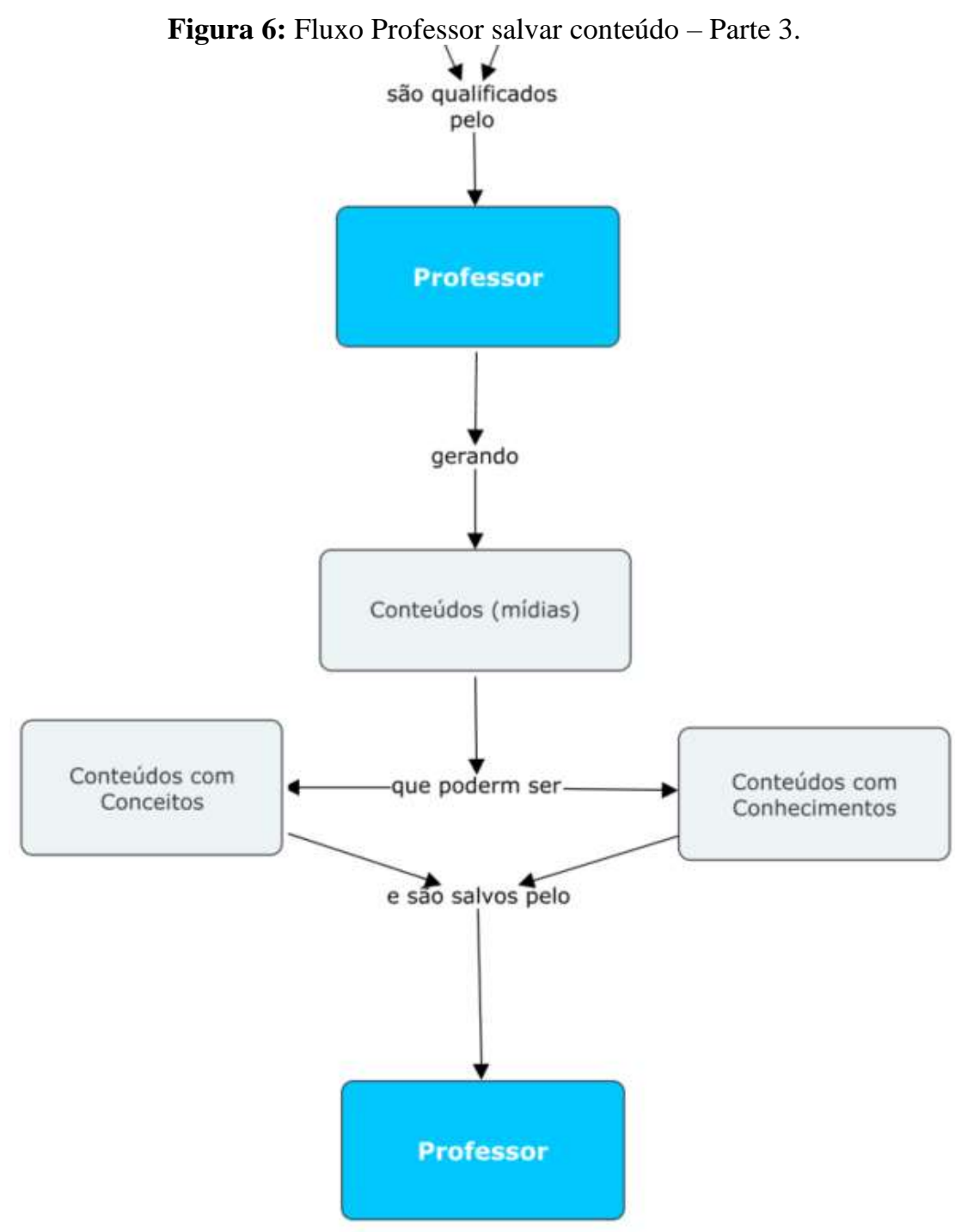

Fonte: Autores (2021).

\subsection{Fluxo do Aluno}

O aluno acessa o sistema e visualiza os conteúdos que foram disponibilizados pelo professor, que podem abordar conceitos e conhecimentos, o aluno inclui no cronograma que gerado pelo MMEEBB os conhecimentos os que possui dúvidas e seleciona o tipo de mídia que tem preferência, que pode ser vídeos, arquivos .pdf, links, áudios e infográficos, como apresentado na Figura 7. 
Figura 7: Fluxo Aluno - Parte 1.

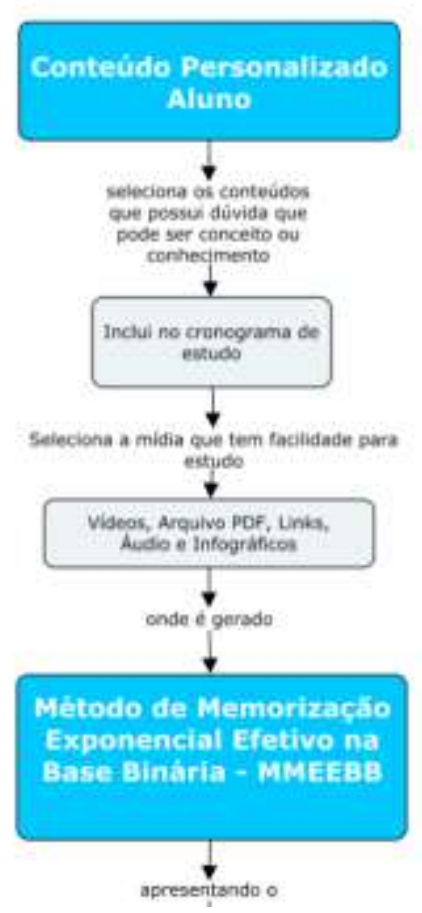

Fonte: Autores (2021).

Ao realizar a seleção dos conteúdos que possui dúvidas é gerado o intervalo do reforço do aprendizado, seguindo o que o MMEEBB propõe. Onde é apresentado para o aluno o intervalo de memorização do conteúdo de acordo com a data de inclusão. Dessa forma o aluno visualiza o conteúdo que tem que recordar sempre que abre o sistema. Caso esse conteúdo já esteja consolidado na memória do aluno e o mesmo já tenha segurança em aplicá-lo, o mesmo pode ser excluído do cronograma de memorização, esse fluxo pode ser visualizado na Figura 8.

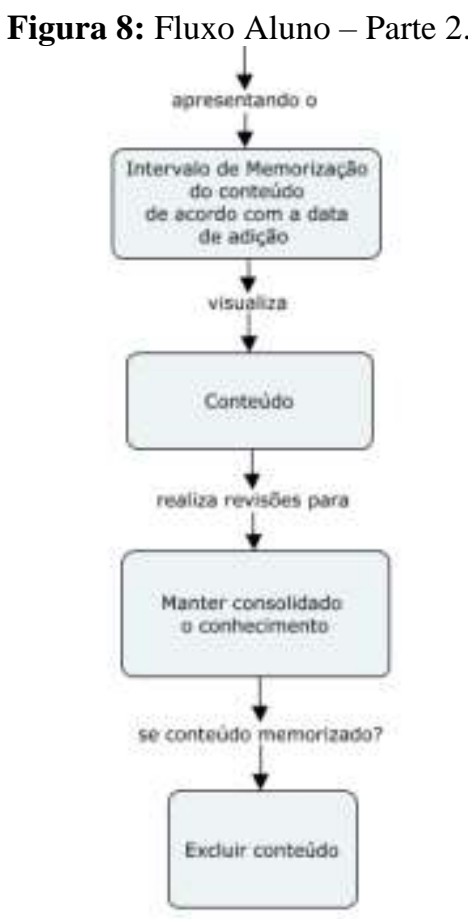

Fonte: Autores (2021). 


\section{Resultados}

A seguir, serão apresentadas algumas funções do sistema web para apoio na aprendizagem, utilizando métodos efetivos para construção do conhecimento. Inicialmente será apresentada a interface do Professor e posteriormente do aluno.

\subsection{Interface Professor}

O usuário autenticado no sistema com o perfil Professor é redirecionado para uma dashboard, nessa área será possível visualizar resumos das disciplinas nos quais o usuário já cadastrou. Assim como a quantidade de alunos na plataforma, quantidade de professores, disciplinas, área de conhecimento, conteúdos programáticos, é apresentado um resumo geral dos dados cadastrados no sistema.

O processo inicial que professor deve realizar para começar a utilizar a plataforma é o cadastro referente aos dados da disciplina. Alguns parâmetros devem ser inseridos antes de cadastrar as informações sobre a disciplina e seu conteúdo; uma delas é a área de conhecimento. A área de conhecimento é importante, pois outros cursos podem compartilhar de alguns conteúdos e esses podem ser disponibilizados de modo genérico.

Outro parâmetro que deve ser inserido para iniciar o cadastro da disciplina é o tipo de material, trata-se de um item muito importante para que o aluno consiga seguir um fluxo de aprendizagem de acordo com a mídia que ele tem maior facilidade para estudar. Realizadas as parametrizações da inserção da área de conhecimento e tipo de material é possível realizar a inserção das informações da disciplina e, consequentemente, dos seus materiais vinculados. A Figura 9 mostra como é possível gerenciar essas informações relacionadas a disciplina.

Figura 9: Gerenciar cadastros de disciplinas no sistema.

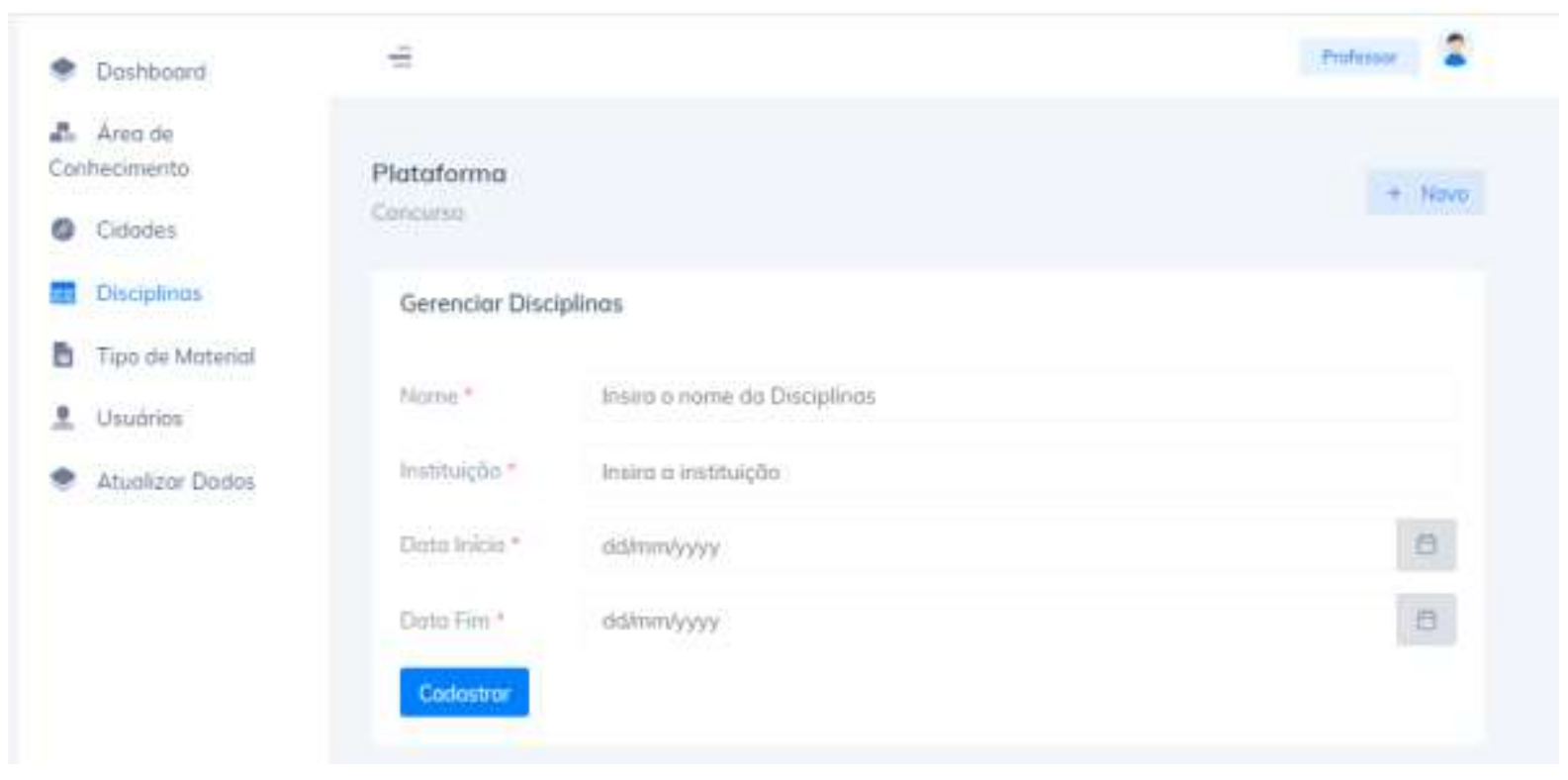

Fonte: Autores (2021).

Na função para inserção dos dados da disciplina é necessário inserir o nome da disciplina, instituição, data início e data fim. A informação da data é muito importante para a geração do cronograma de memorização do aluno utilizando o MMEEBB, para ser possível seguir o intervalo que é proposto no método para efetivar a aprendizagem. Ao cadastrar as informações sobre a disciplina, o módulo para inserir o conteúdo programático e material é habilitado, como apresentado na Figura 10 . 
Figura 10: Gerenciar Conteúdo.

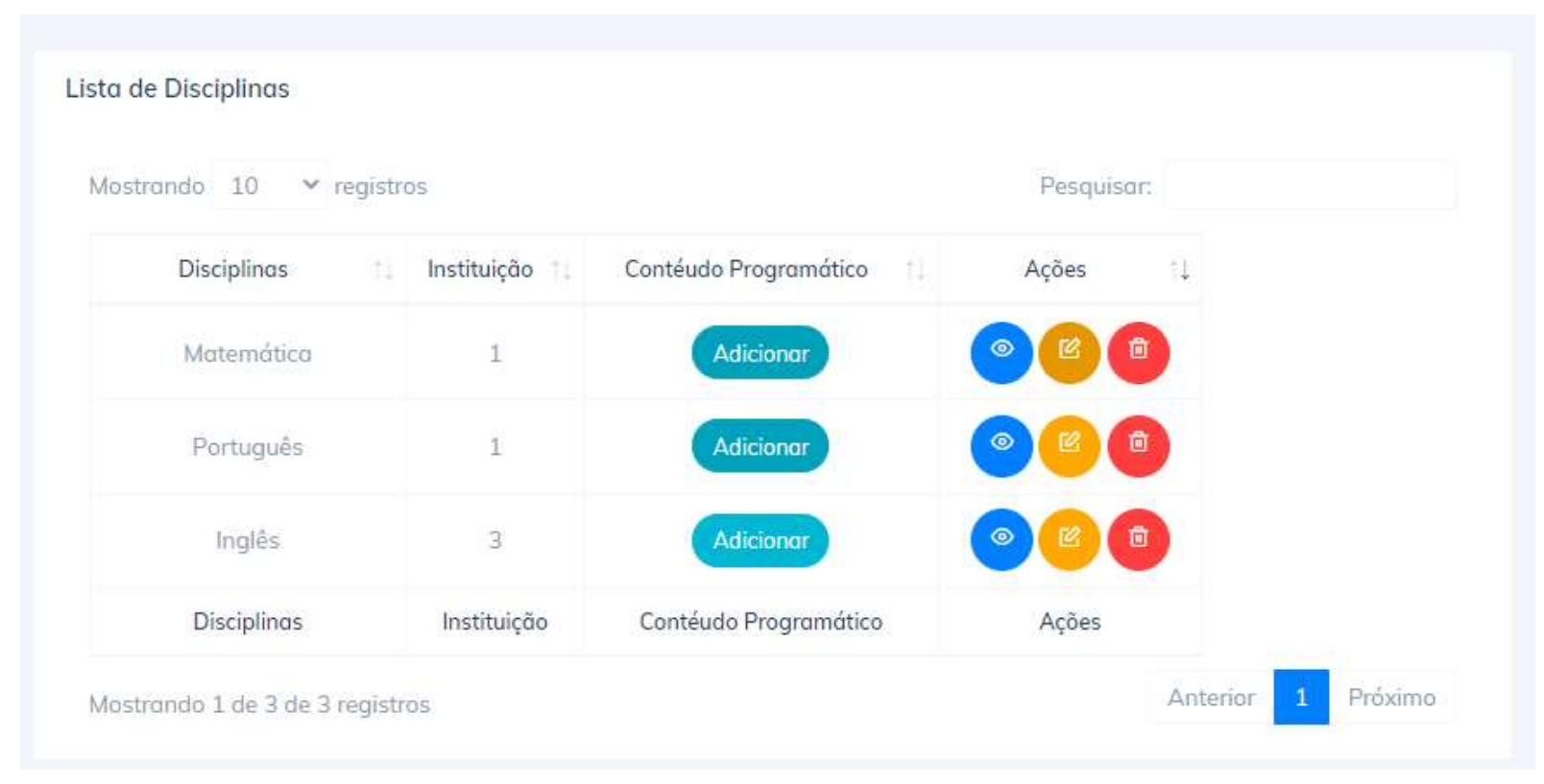

Fonte: Autores (2021).

Foram cadastradas as disciplinas de Matemática, Português e Inglês como exemplos. É possível vincular o material através da função Conteúdo Programático, como pode ser observador na Figura 10. Nesse momento, o professor necessita ter muito bem definido o conteúdo que será disponibilizado para os alunos. Seguindo as premissas do MCE, para que o professor consiga estabelecer um funtor, comunicação entre ele e o aluno, é necessário que nas duas categorias possua objetos e morfirmos similares.

No aluno pode conter dúvidas de entendimento referentes ao novo conhecimento, por isso a necessidade de inserção de conteúdos programáticos complementares ao conteúdo macro. Isso estabelece que não pode faltar ao aluno objetos e morfismos precedentes ao entendimento do novo conhecimento para que o funtor que mapeará o mesmo possa ser estabelecido. Simplificando ainda mais, não pode faltar o conhecimento dos pré-requisitos exigidos para se iniciar o aprendizado do conteúdo novo. Essa informação foi destacada no referencial teórico que aborda o Mapa de Conhecimento Estruturado - MCE.

É importante nesse o momento que o professor, na inserção do material no conteúdo programático, classifique os prérequisitos de objetos de (conceitos e definições) e morfismos (conhecimentos). Um exemplo na disciplina de português, ensinar acentuação, é que o aluno já tenha um requisito inicial que é formar uma palavra. Para tanto, é necessário, na acentuação, inserir um conteúdo complementar sobre construção das palavras; esse processo de complementação será manipulado pelo morfismo. A inserção do material no conteúdo é bem intuitiva: trabalhou-se com o conceito de empatia no sistema para que se tudo seja o mais simples para manipulação do usuário, ou seja, de fácil entendimento.

É possível inserir mais de um material vinculado ao conteúdo programático e complementar. Na Figura 11, é possível visualizar a gestão dessa inserção. Indica-se inserir todos os tipos de materiais no conteúdo, pois pode haver alunos que aprendem melhor por meio de uma leitura, outros possuem facilidade assistindo a um vídeo ou ouvindo um podcast. Portanto, outra premissa para que o sistema web alcance a efetivação do aprendizado é que seja disponibilizado todos os tipos de mídias do conteúdo, como imagens, arquivos em pdf, infográficos, vídeos e áudios. 
Figura 11: Gerenciar cadastro de materiais vinculados ao conteúdo.

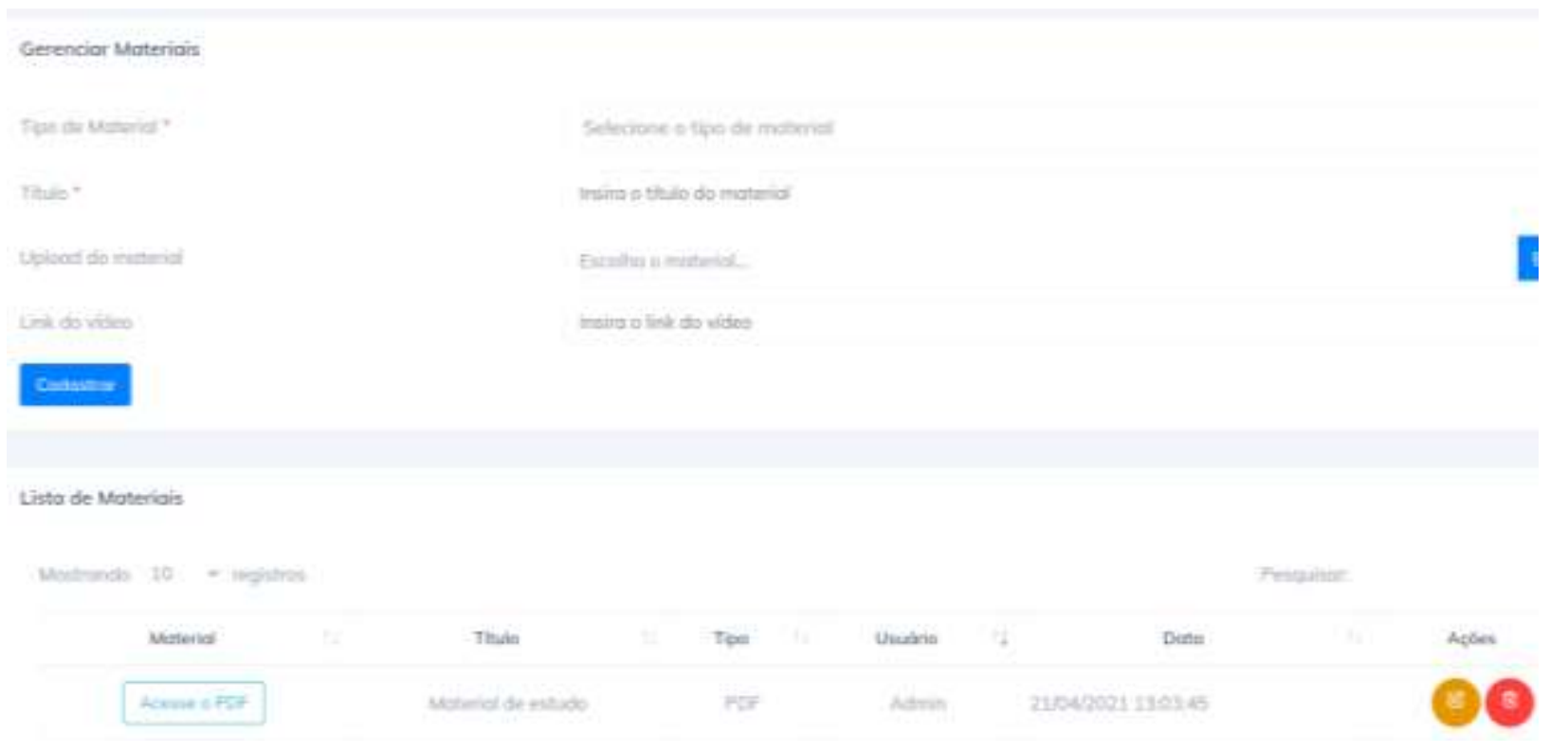

Fonte: Autores (2021).

O professor através desse processo conseguirá disponibilizar o material para que o aluno acesse as informações, visualize os conteúdos que tem dúvida e os inclua no seu raio de ignorância, para alcançar o raio de conhecimento. Dessa forma, esse passo é muito importante para o sucesso do aluno, pois se o conteúdo disponibilizado for divergente do teor do que o aluno será cobrado, o aluno não alcançará seus objetivos. Atenção deve se ter também aos conteúdos que exigem prérequisito, pois estes podem gerar dúvidas no aluno ao iniciar a jornada de aprendizagem no sistema, que pode buscar informações em outras fontes de ensino que usam de métodos diferentes da aplicabilidade daquele conceito/conhecimento. No próximo item serão apresentados o cenário e as ações dos alunos no sistema.

\subsection{Interface Aluno}

Seguindo o intervalo de reforço de aprendizagem proposto pelo MMEEBB, na tela inicial, quando o aluno autentica seu acesso ao sistema, poderá visualizar o cronograma de estudos gerado sistema web de acordo com a proposta do método. Seguem na Figura 12, as notificações de revisão de conteúdo, dos quais ele já marcou que possui dúvida. Essas notificações são muito importantes para que o aluno mantenha perene o conhecimento que foi estudado, realizando revisões diariamente, para que no momento do exame não tenha nenhuma dúvida. 
Figura 12: Notificações geradas para Revisão de Conteúdo.

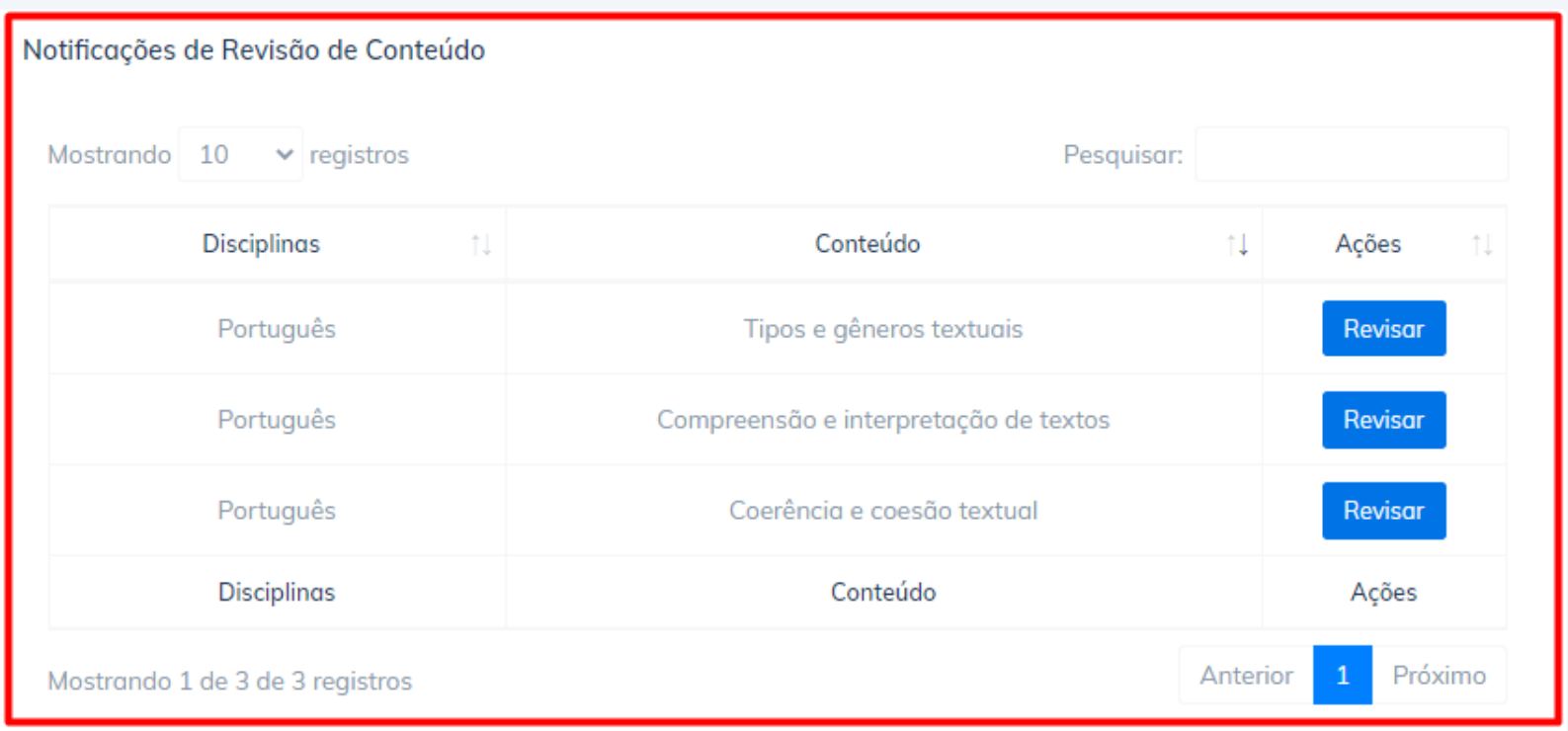

Fonte: Autores (2021).

Como o MMEEBB coloca, a curva de memorização mostra quando o indivíduo tem que recordar a informação. Esse é o objetivo: disponibilizar as notificações assim que o aluno abre o sistema com as revisões que deve realizar naquele dia. $\mathrm{O}$ objetivo é sempre manter consolidado o conhecimento de acordo com o reforço $2 \mathrm{n}$. É através do Intervalo de Reforço de Aprendizagem - IRA que será possível completar até mesmo outros sistemas, de qualquer área, que disponibilizam conteúdo. O IRA permite ao aluno ter equilíbrio no que deseja manter perene para realizar os testes que são exigidos em qualquer situação.

Sendo assim, o aluno consegue encontrar o centro de gravidade de equilíbrio, com conteúdo compatível a suas dúvidas e um intervalo automático de conteúdo de maneira que não tenha que preocupar com o momento de recordar, pois o sistema irá gerar seu cronograma de modo automático de acordo com a data de inserção do conteúdo. Portanto, o aluno terá vários conhecimentos com pontos de gravidade e assim ele encontrará o equilíbrio e não irá aplicar o conhecimento inseguro ou com dúvidas. Ao clicar em revisar o aluno visualiza o conteúdo da seguinte forma, como apresentado na Figura 13, com várias opções de mídias. 
Research, Society and Development, v. 10, n. 11, e467101119824, 2021

(CC BY 4.0) | ISSN 2525-3409 | DOI: http://dx.doi.org/10.33448/rsd-v10i11.19824

Figura 13: Lista de conteúdos disciplina português.

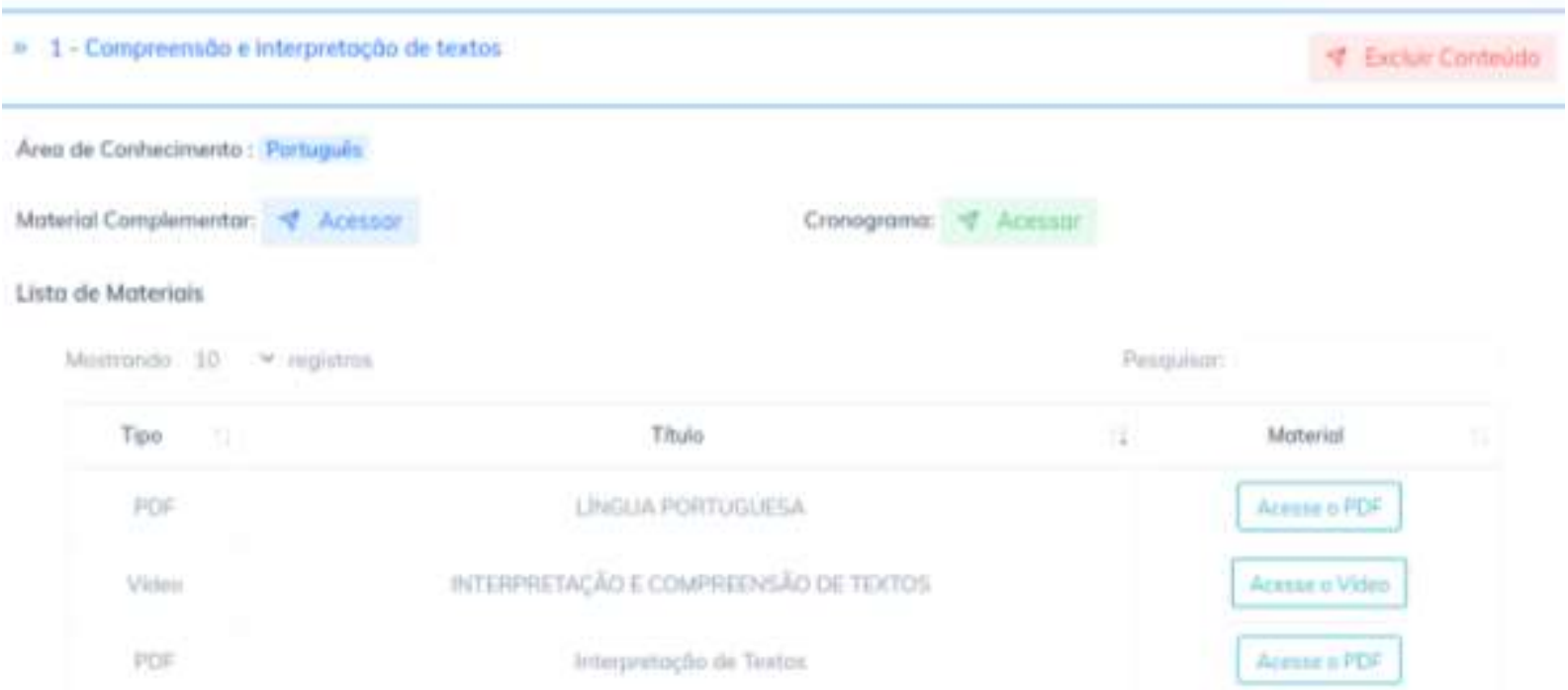

Fonte: Autores (2021).

E se o aluno necessitar visualizar o cronograma detalhado gerado pelo MMEEBB, ele pode clicar no link acessar do cronograma, que está ilustrado da Figura 14. Dessa forma será apresentado uma lista de quando o aluno deve revisar um conhecimento, onde a data inicial que foi adicionado o conteúdo é igual a quando ele iniciou esse novo conhecimento. Observa-se ainda que segue o intervalo do MMEEBB onde o último conteúdo ministrado é igual a $2^{14}$ onde se ele iniciar na data do dia 03/06/2021, como apresentado na Figura 14 a última recordação será em dezenove de fevereiro de 2111.

Figura 14: Cronograma MMEEBB.

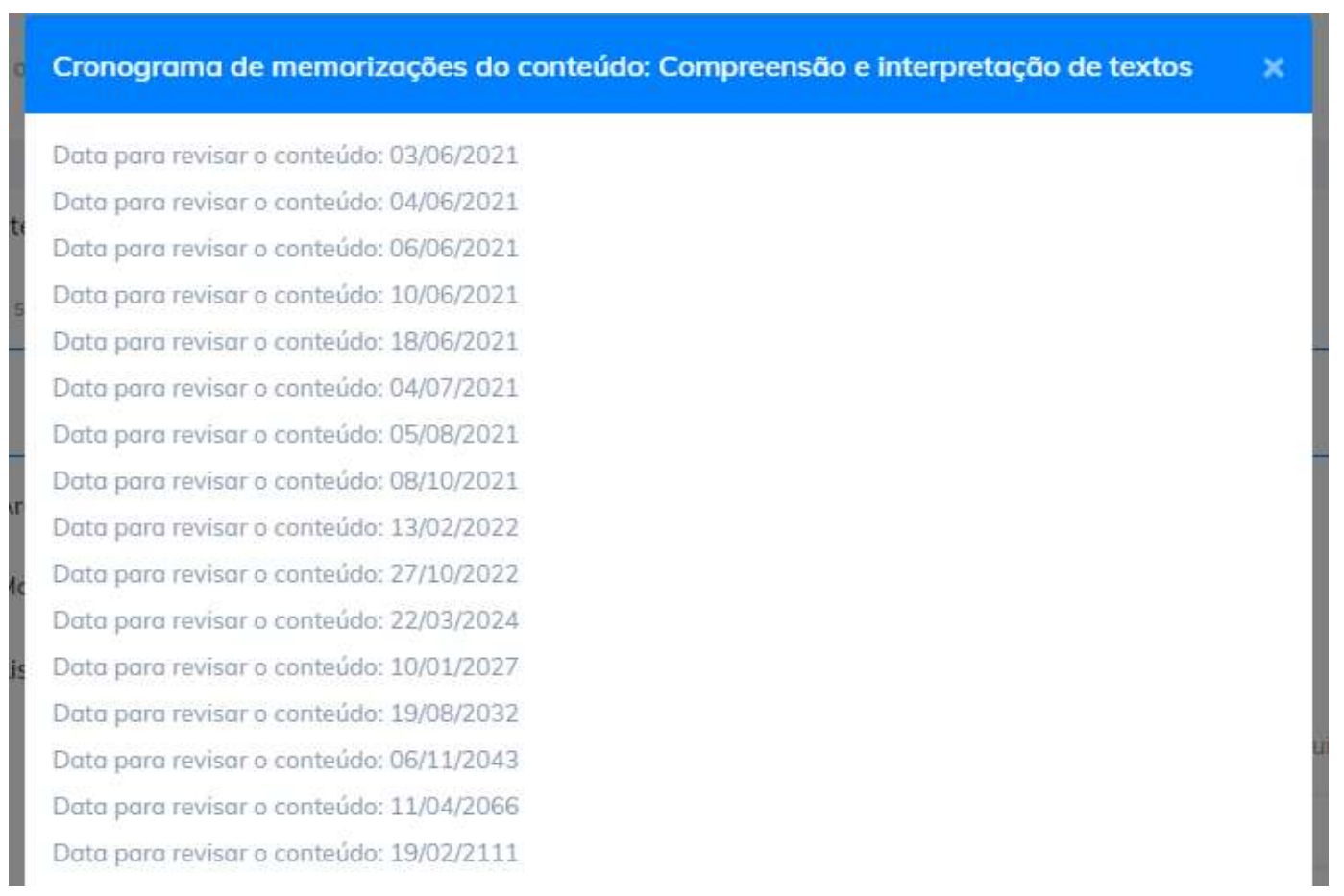

Fonte: Autores (2021).

O ponto de equilíbrio é o que se busca com o método e o sistema web para apoio da aprendizagem ao aluno, que 
recorde e a cada dia consolide o conhecimento na memória, reconsolidando esse conhecimento. É o indivíduo ter o conhecimento na memória e ter consciência do que ele sabe e não sabe, ou seja, onde possui segurança do conhecimento que tem, ele pode arriscar um desafio.

É o aluno ter segurança em estudar um conteúdo e ter garantia que realmente aprendeu e com o MMEEBB isso é possível, seguindo corretamente os intervalos de reforço de aprendizagem. Dessa forma os Professores conseguem ter também acompanhar a evolução sobre o conteúdo que o aluno está recebendo e que o mesmo está seguindo um método efetivo com os reforços de aprendizagem.

\section{Conclusão}

Este trabalho apresenta as potencialidades de um sistema web que implementa uma interface entre o professor e o aluno através do ensino remoto, que foi implantando e está sendo utilizando nesse período de pandemia. Onde possibilita a ambos um equilíbrio, tanto para o aluno, quanto para o professor. No qual o professor disponibiliza material que é realmente do seu domínio e competente ao que ele deseja transmitir para o aluno, evitando que o aluno acesse materiais divergente do conteúdo que é ministrado pelo professor e que o aluno consiga abstrair desse conteúdo um conhecimento que vai ficar perene em sua memória utilizando o MMEEBB.

Como projeto futuro planeja-se a inserção de avaliações, que vão ser desenvolvidas e inseridas pelo professor da disciplina. Através dessas avaliações será possível avaliar se o aluno está apto ou não para dar sequência ao próximo conhecimento, ou se faz necessário realizar mais reforços de aprendizagem.

Está sendo desenvolvido também uma versão mobile do sistema para aluno, principalmente para auxiliar no envio das notificações sobre qual conteúdo o aluno deve recordar seguindo o MMEEBB, para que ele possa receber a notificação e acessar o conteúdo de qualquer dispositivo. O sistema web para apoio a aprendizagem está em sua primeira versão, podendo ser adaptado e otimizado a partir dos resultados, bem como das demandas do mercado e parcerias. $\mathrm{O}$ sistema pode ser utilizado e aplicado em qualquer área, desde para os alunos dos anos inicias, a graduação, estudos para residência médica, concursos, entre outros.

\section{Referências}

Agência Brasil, 2020. IBGE: desemprego na pandemia atinge maior patamar em agosto. https://agenciabrasil.ebc.com.br/economia/noticia/2020-09/ibgedesemprego-na-pandemia-atinge-maior-patamar-em-agosto

Brasil, 2020. Entra em vigor estado de calamidade pública no Brasil. Governo Federal - Governo do Brasil, 2020. https://www.gov.br/planalto/ptbr/acompanhe-o-planalto/noticias/2020/03/entra-em-vigor-estado-de-calamidade-publica-no-brasil

Carneiro, I. B. (2017). Projeto de aplicação de software para efetivação da comunicação em língua inglesa entre não-nativos, nativos e máquinas utilizando a metodologia do MCE e MMEEBB aplicada ao Globish. Dissertação (Mestrado em Tecnologias, Comunicação e Educação) - UFU, https://repositorio.ufu.br/bitstream/123456789/19798/1/ProjetoAplicacaoSoftware.pdf

Cowan, Nelson. (2001). The magical number 4 in short-term memory: a reconsideration of mental storage capacity. Behavioral and Brain Sciences.

Dias, D. C., Costa, Nayara da Silva, \& Lima, L. V. (2009). Projeto e implementação de recursos didáticos multimídia interativos para melhoria do ensino de disciplinas de engenharia de computação. In: ICECE’2009 International Conference on Engineering and Computer Education, 2009, Rio de Janeiro: Educating Engineers for Innovation. v. 1. p. 84-89.

Dias, E., \& Pinto, F. C. F. (2020). A Educação e a Covid-19. Ensaio: aval. pol. públ. Educ., 28(108), 545-554.

Ferreira, D. C. M., Lima, L. V., Camargo Junior, H., \& Costa, N. da S. (2014). Mapas de conhecimentos Estruturado: uma proposta de uma nova abordagem metodológica de ensino e aprendizagem. Educere et Educare (versão eletrônica). 9, 505-514.

Flashcard, (2020) “The forgetting curve,” Flashcard Learner. http://www.flashcardlearner.com/articles/the-forgetting-curve.

Gil, A. C. (2002). Como elaborar projetos de pesquisa. (4a ed.), Atlas.

Kemp, S. (2021). Digital 2021: The latest insights into the state of digital. We Are Social. https://wearesocial.com/ /2021/01/digital-2021-the-latest-insightsinto-the-state-of-digital 
Research, Society and Development, v. 10, n. 11, e467101119824, 2021

(CC BY 4.0) | ISSN 2525-3409 | DOI: http://dx.doi.org/10.33448/rsd-v10i11.19824

Lima, S. F. de O., Barbosa Filho, R., Lima, L. V. \& Camargo Júnior, H. (2013). Mapas de Conhecimento: uma ferramenta de aprendizagem por meio de Card Informativo como instrumento de ensino. Revista Unopar Científica Ciências Humanas e Educação. 14, 05-14.

Lupion, B. (2020). Como a pandemia de coronavírus impacta o ensino no Brasil. https://www.dw.com/pt-br/como-a-pandemia-de-coronav\%C3\%ADrusimpacta-o-ensino-no-brasil/a-53008677

Monteiro, S. S. (2020). (Re)inventar educação escolar no brasil em tempos da COVID-19. Rev. Augustus25 (51).

Morais, L. (2020). Aulas particulares viram alternativa em meio às incertezas da volta das escolas. https://www.otempo.com.br/cidades/aulas-particularesviram-alternativa-em-meio-as-incertezas-da-volta-das-escolas-1.2342756

OPAS (2021). Histórico da pandemia de COVID-19. https://www.paho.org/pt/covid19/historico-da-pandemia-covid-19

Portal Fio Cruz, (2021). Impactos sociais, econômicos, culturais e políticos da pandemia. https://portal.fiocruz.br/impactos-sociais-economicos-culturais-epoliticos-da-pandemia

Reis, A. V. S.A, Amaro, D. \& Reis, F. (2020). Ensino remoto: o lanejamento das aulas é, mais do que nunca, uma necessidade. https://revistaensinosuperior.com.br/planejamento-das-aulas/

Rocha, F. S. M., Loss, T. B., Almeida, B. L. C., Motta, M. S. \&Kalinke, M. A.(2020). O uso de tecnologias digitais no processo de ensino durante a pandemia da Covid-19. Interacções16(55).

Ruprecht, T. (2020). Coronavírus: 6 medidas antes de flexibilizar o isolamento social. Veja Saúde. https://saude.abril.com.br/medicina/coronavirus-medidasflexibilizar-isolamento-social/

Salomão, M. (2021) DF registrou cerca de 1.300 demissões de professores na pandemia. https://www.correiobraziliense.com.br/euestudante/educacaobasica/2021/01/4900418-df-registrou-cerca-de-1-300-demissoes-de-professores-na-pandemia.html

Silva, M. C. (2020). Proposta de um sistema em nuvem com recursos multimídia para apoio à Aprendizagem Instrumental de Línguas. Dissertação (Mestrado em Engenharia Elétrica) - UFU, https://repositorio.ufu.br/bitstream/123456789/30023/1/PropostaSistemaNuvem.pdf

Silva, M. D. (2017). Proposta de um guia metodológico e software para quantificação qualitativa na avaliação efetiva do aprendizado em AVAS e ensino presencial. Dissertação (Mestrado em Tecnologias, Comunicação e Educação) - UFU, https://repositorio.ufu.br/bi tstream/123456789/18306/1/PropostaGuiaMetodologico.pdf 